This is a post-print (author's final draft) of an article in the journal Biosemiotics (2013) 6:585-606. DOI 10.1007/s12304-013-9192-6. [Original page numbers between square brackets]. Details of the printed version are available at http://link.springer.com/article/10.1007\%2Fs12304-013-9192-6\#page-15

\title{
From Sound to Music: An Evolutionary Approach to Musical Semantics
}

\author{
Mark Reybrouck
}

\begin{abstract}
This paper holds an evolutionary approach to musical semantics. Revolving around the nature/nurture dichotomy, it considers the role of the dispositional machinery to respond to sounding stimuli. Conceiving of music as organized sound, it stresses the dynamic tension between music as a collection of vibrational events and their potential of being structured. This structuring, however, is not gratuitous. It depends on levels of processing that rely on evolutionary older levels of reacting to the sounds as well as higher-level functions of the brain, which allow listeners to emancipate themselves from mere acoustic processing of sounds to the level of epistemic interactions with the sounding music. These interactions are partly autonomous and partly constrained, but they all stress the realization of systemic cognition in the context of a living system's interactions with the environment. As such, listeners can be conceived as adaptive devices, which can build up new semiotic linkages with the sounding world.
\end{abstract}

Keywords: musical epistemology - musical sense-making - nature/nurture - biology/culture music and evolution - adaptive behavior - musical universals - music and emotion

\section{Introduction}

[585] Is there a difference between sound and music? Is music to be found in the natural world, with natural sounds being so organized that they sound as music, or does it need an intervention by the human mind? Is music an 'ontological' category or should we rely on 
'epistemic' interactions with the sounds? And is music something that is merely listened to or something that involves an activity of sound production or other manifest reactions to the sounds? These questions revolve around the conception of music as organized sound with the organization being part of the intrinsic structure of the sounds or being imposed on them by human minds. As [586] such, there is a dynamic tension between music as a collection of vibrational or resonating events and their potential of being structured. This structuring, however, is not gratuitous. It depends on levels of processing that rely on evolutionary older levels of reacting to the sounds as well as higher-level functions of the brain. These levels are not mutually exclusive but hold massive interrelations with higher levels being superposed on lower ones and lower levels providing input for the higher ones. As such, there is an interesting complementarity of a bottom-up and top-down approach.

At the lowest level, there is mere reactivity, with senses functioning to arouse sensations. At a somewhat higher level, listeners do not rely merely on senses but on perceptual systems, which are tuned to the information that is considered to be useful. Perception, at this level, is not to be explained in mechanistic terms of stimuli and reactions, but in terms of active systems that search for information. At a still higher level, there is a whole gamut of cognitive elaborations, which are the outcome of epistemic interactions with the sounds. In addition, however, to these acquired cognitive influences, there is a deeper affective domain within the organization of the brain to which cognition is subservient and which make the brains such receptive vessels for the emotional power of music (Panksepp \& Bernatzky, 2002). Human beings, as sentient and conscious beings, are thus equipped with a dispositional machinery that enables them to cope with music as a sounding environment, both as the result of innate mechanisms and acts of deliberate attention that are the outcome of a learning history. As such, music users - to use a generic term that embraces both listeners, performers, improvisers and composers - can rely on mechanisms for perception and sense-making that are both common to the human species in general as well as typical for individual music users.

Music perception, in this view, is not simply describable in univocal terms. It revolves around two major dichotomies that run across the mechanisms of reception and production of music: (i) the nature/nurture dichotomy and (ii) the biology/culture dichotomy. As to the nature/nurture dichotomy, there has been a long debate which has colored musical discussions for decades about the innate versus acquired character of musical perception and sense- 
making (see Reybrouck, 2008 for an overview), referring respectively to the neurobiological claims of wired-in circuitry (nature) for perceptual information pickup as against the learned mechanisms for information processing and sense-making (nurture). As to the biology/culture dichotomy, the biological position argues for wired-in mechanisms of reactivity to sounds or music, while the cultural position argues for variables that are the outcome of immersion in a culture. The antithesis, however, has begun to break down with developments in evolutionary theory and ethological research, which state that cultures may vary, but that the human capacity for culture appears to be a human universal, which is part of our biological heritage (Blacking, 1995; Cross, 2009-2010). It is fruitful, therefore, to consider the dependency between both variables and to think in terms of a 'gene-culture coevolutionary theory' (Feldman \& Laland, 1996; Lumsden \& Wilson, 1981). Music users, in fact, are biological organisms, which are immersed in a culture, but even culture did not evolve in a vacuum. Both culture and music are born out of man's animal characteristics, which are rooted in the biology of perception and cognition, and this may be universal to a great extent (Goldschmidt, 1959; Panksepp \& Bernatzky, 2002; Peretz, 2006). Though there are at least some mechanisms of musical sense-making that rely on genetics rather than on culture, there seems [587] to be a lot of commonality at the level of 'acquired habits' and 'learned responses' as well, which can spread across the earth and become universals without genetic basis. As such, it may be interesting to look for mechanisms of music perception and production, which are so general that they are accessible to common music users all over the world.

In what follows, I will argue for an evolutionary approach to musical sense-making in an attempt to go beyond the above-sketched dichotomies, with a major focus on the transition from acoustic-emotional sensibilities to musical meaning. Emotional processing, in fact, holds a hybrid position: it is the place where nature meets nurture with emotive meaning relying both on pre-programmed reactivity and on culturally established patterns or conventions of coping with the sound (Oatley, 1992). Many dynamic aspects of music, further, probably gain access to human emotional systems quite directly without having to be processed propositionally (Panksepp \& Bernatzky, 2002).

Human beings, in this view, are wired-in to respond emotionally to certain features of stimuli in the world, but emotional reactions cannot be exhaustively explained by pre-programmed reaction patterns alone. Music users, accordingly, are not merely reactive machines but 
adaptive devices that are able to modify their epistemic relations with the outer world, and this at several levels of dealing with the sounds: the level of sensation and perception, the level of sound production and manifest reactions to the sounds, and the level of mental processing of the sounds (Reybrouck, 2005a, 2006a). The adaptation, further, can be considered at the large-scale level of the human beings as a species in the animal kingdom (phylogeny), but also at the level of an individual's life history (ontogeny).

\section{Music as an evolutionary adaptation}

Conceiving of music as an evolutionary adaptation calls forth questions about the evolutionary origins of music: where does music come from? and why do we have music at all? Both questions have been elusive up to now. Music, in fact, has emerged spontaneously and in parallel in all known human cultures and societies, but we do not know when it emerged because there are no fossil records of singing and music making. Archeological evidence shows a continuous record of musical instruments, dating back to at least 30,000 years (D'Errico et al., 2003). The quest for the origins of music, however, is restricted mostly to an evolutionary account. It is a central topic of current musicological research with a number of seminal contributions (Cross, 2001 a, b; 2003a, b; 2009-2010; Hauser \& McDermott, 2003; Huron, 2003; McDermott \& Hauser, 2005; Mithen, 2005; Wallin, 1991; Wallin et al. 2000; Zatorre \& Peretz, 2001) and special issues in major journals (Annals of the New york Academy of Science , 2001; Cognition, 2006, Music Perception 2005, Musicae Scientiae, 2009-2010, and Nature neuroscience, 2003). There is, further, also an approach from comparative musicology and the anthropology of music (Merriam, 1964; Nettl \& Bohlman, 1991), which stresses the observable fact that music-making is a fundamental and universal attribute of the human species. It is ubiquitous not only across human societies but across all members of those societies (Blacking, 1973). It is possible, therefore, to conceive of music as a universal phenomenon with adaptive power. According to Miller (2000, see also Trehub, 2003a), music [588] exemplifies many of the classic criteria for complex human adaptation: (i) no culture in any period of recorded history has been without music (universality); (ii) the development of musical abilities is orderly; (iii) the ability is widespread in the sense that almost every normal adult can appreciate music and carry a tune (basic perceptual and performing skills); (iv) adults can recognize thousands of melodies, 
implying specialized memory; (v) special-purpose brain mechanisms are involved (located in the cortex) ; (vi) there are analogues in the signals of other species such as songbirds, gibbons, and whales, raising the possibility of convergent evolution; and (vii) music can evoke strong emotions which implies receptive as well as productive adaptation.

The list brings together a number of approaches, conflating biological and cultural claims. The strongest argument that music is an important evolutionary adaptation, however, comes from the developmental perspective (Trainor \& Schmidt, 2003). Caregivers around the world sing to infants in a style that is distinct from other types of singing (motherese) and young infants are very responsive to this kind of music.

This brings us to the fundamental question why human beings are musical. The question is not trivial, as there seem to be processing algorithms for music perception, which are part of our genetic heritage. Music, thus, seems to correspond to an impulse that emerged early in human evolution; it is present and functional early in human development; it has an important emotional impact; and it resides, at least in part, in specialized brain areas (Peretz, 2006). This leads us to a second question: Does music have any survival value? And can we conceive of music as an evolutionary adaptation? Or stated in other terms: What adaptive function or evolutionary advantage was served by music in ancestral activities?

There is no simple answer to this question, as adaptation can be approached from different perspectives. There is, first, the 'scale of description' with a distinction between adaptation at a larger evolutionary scale (the phylogenetic approach) as against a description of the human development at the level of individual human beings from newborn to old age (the ontogenetic approach) (Gould, 1977). The concept of adaptation, further, is a 'biological concept'. It allows an organism to change itself in order to survive in its environment (Fleagle, 1999). As such, the organism can be considered as an adaptive device that can modify itself in order to cope with the solicitations of a challenging surrounding world. Adaptation simply provides the organism with better tools for coping with the world, with the evolution of sense organs and body appendages as natural examples. An organism or device, however, can be 'semantically' programmable as well in order to change its semantic relations with the world. The concept of adaptation can thus be translated to the realm of cognition as well, as did Piaget (1967). He conceived of adaptation as a mechanism for equilibration. Through the key concepts of assimilation and accommodation he made an 
attempt to explain the basic mechanisms of adaptation. The mind primarily 'assimilates', that is, perceives and categorizes experiences in terms of what it already knows. Cognitive assimilation thus comes about when a cognizing organism fits an experience into a cognitive structure it already has. Only if the result of this process creates a perturbation, a review is initiated that may lead to an 'accommodation'. As such, it may give rise to changes in an existing structure or to the formation of a new structure. Once these new structures are installed, however, the cognizer has adapted him/herself to achieve a new state of equilibrium.

[589] This brings us to the question whether music can be conceived also as an evolutionary adaptation. Does music has survival value or is it to be considered merely as a by-product of other evolutionary adaptations? Is music to be characterized as the product of a generalpurpose cognitive architecture (Bregman, 1990; Handel, 1989; Krumhans1, 1990, see also Peretz, 2006 for an overview) or is it assembled from other faculties that were not originally designed for its purposes (Pinker, 1997)? Should we conceive of exaptation rather than of adaptation in order to describe behaviors and structures, which are not directly specified in the genome, but which are alterations of the way existing adaptations are used (Gould \& Vrba, 1982)? Exaptations may or may not initially confer selective advantage, but they can be considered as 'secondary adaptations' when they become more efficient at their behavior, or more readily produced in new members of a species (Dean, Byron \& Bailes, 2009-2010). Music, in this view, should be an evolutionary parasite of auditory, vestibular and proprioceptive development with the adaptive value of those sensory modalities lying in the promotion of, e.g., infant-mother bonding, motor control, and language (Parncutt, 20092010).

The question as to the adaptive function of music and the related question of music's origins remains open up to now. It warrants further investigation (see Wallin, Merker, and Brown, 2000). There are, however, some theories in favor of an evolutionary adaptation. According to Huron (2003), there are at least eight broad evolutionary theories that can be identified: (i) music served to attract sexual partners, as a kind of mate selection, (ii) music might be helpful in promoting social cohesion, (iii) music might contribute to the coordination of group effort, (iv) listening to music helps perceptual development as an exercise for better hearing, (v) singing and other music-making activities provide opportunities for refining motor skills, (vi) music might reduce interpersonal conflict and is thus helpful in conflict resolution, (vii) music might provide a benign form of safe time passing, and (viii) through the use of folk ballads 
and epics, music might have originated as a useful mnemonic conveyance for transgenerational communication.

The list is not exhaustive. There are other possible functions - some of them related to the listed ones - such as the extension of individuality in community (Blacking, 1987); enhancing cooperation and educating the emotions and the senses to generate greater sensory awareness and social cooperation; the emergence of regulatory processes for other social dynamics; the coregulation of affect by parent and child in caregiver-infant interactions (Dissanayake, 2000; Gratier, 1999); the induction of trance states (Rouget, 1985), emotional and motor arousal (Levitin, 2006); the stirring, animating and coercive power of music; and the emergence of intersubjective communication.

Most of these functions can be subsumed under the biology/culture dichotomy. Music, in fact, is able to induce biological and physiological reactions in the music user as a biological organism as well as promoting collective and communal group resonance and synchronization. The biological claims, however, are so general that they can be generalized across human cultures. It brings us to the tedious question whether we can conceive of music in terms of universals.

\section{Musical universals between nature and nurture}

Music making is a fundamental and universal attribute of the human species. But does this mean that we can speak of universals with respect to music? Music, as studied mainly in [590] academic circles, is typically seen as a social construct that varies from culture to culture, with a corresponding rejection of cross-cultural quests for universals underlying this diversity. The stance of a famous ethnomusicologist as Blacking (1973) is typical of this approach: the conventions of musical systems and people's emotional response to them are cultural constructs; even within well-defined cultures, there are so many idiosyncrasies and subjectivities that the mere claim of universal meaning in music seems problematic. Yet, he accepted the existence of psychophysical commonalities between disparate tonal systems, as well as the major role of relatively unchanging biological processes of aural perception in discovering patterns of sound. 
The term psychophysical, however, has several meanings. In a strict sense, it refers to the correlations between acoustic signals and their perceptual processing, embracing the conversion between the acoustic level of musical stimuli and the level of meaning, as well as the lawfulness or arbitrariness of this transformation. In the literature on music psychology, however, the term has been used rather loosely to refer to physical properties of music (e.g. tempo, pitch range, melodic and rhythmic complexity) that may be defined and assessed independently of the musical conventions of any particular culture. It represents those qualities, which are not restricted to a particular musical style or culture, and which do not require detailed musical knowledge in order to interpret them or respond to them at an emotional level (Balkwill \& Thompson, 1999). They mainly correspond to those characteristics of music to which basic auditory processes naturally respond. Tempo is an example: it can be measured in beats per minute (bpm), which is a quantifiable measure of occurrence over time, which could apply to any type of stimulus.

There are, further, basic mechanisms of musical sense-making which are general across ages and cultures and which rely on levels of processing that are grounded in our biology (see Drake \& Bertrand 2003, for an overview). As such, there has been a current alignment between musicology and biology with a broadening of the definition of music from a restricted body of musical works to an approach which is both transcultural and transhistorical—from 'music' to 'musics' of the world—and which relies on psychophysical and neurobiological commonalities that are typical hallmarks of Homo Sapiens as one of the major developments of hominid phylogenetic evolution. Typical of this alignment is the quest for universals, which was initiated by the 1970s - two journals published a special issue on the topic: Ethnomusicology $(1971,15,3)$ and The World of Music (1977, 19, 1/2), see Nettl, 2000). More recently, the topic of universals has received renewed attention in 'musicological' research (see Leroy, 2012, Miereanu and Hascher, 1998). But, above all, there is the new field of biomusicology (see Wallin, 1991; Wallin, Merker \& Brown, 2000) which aims at resuscitating the concept of musical universals, in taking full advantage of current developments in Darwinian anthropology (Durham, 1991), evolutionary psychology (Barkow, J., Cosmides, L. \& Tooby, 1992) and gene-culture coevolutionary theory (Feldman \& Laland 1996; Lumsden and Wilson, 1981). It addresses the basic question of the origins of music, and comprises three main branches: evolutionary musicology, neuromusicology and comparative musicology. 
The question, however, remains as to the nature of these universals. Are they grounded in our biology or embedded and immersed in a culture? This brings us to the nature/nurture dichotomy again with as basic question the search for those low-level features of musicality, which are part of our dispositional machinery. Several [591] approaches to collect empirical support have been used up to now, such as developmental studies, comparative studies and neurological evidence.

The' developmental' research takes as its starting point the experimental principle that teases apart those processes that appear to be innate or hard-wired from those that develop with maturation and acculturation. The procedure is quite simple: if young infants, children and adult musicians display similar modes of functioning on particular task, then it can be concluded that the process is innate or at least functional at an early age (Drake and Bertrand, 2003). If substantial adult-infant similarities are evident in the perception of music, accordingly, one could argue that at least some aspects of music processing have a biological basis and that perception of music is inherently biased rather than unbiased. This same principle can be applied to the study of children (developmental research) and intercultural research (comparative research) with the aim to answer the question of the true 'universal' nature of psychological processes in general.

As such, a number of perceptual skills have been identified which appear precociously, with no obvious function in language. This points to the existence of music predispositions, which are likely to be genetically prewired. Especially the 'newborn infant studies' and their processing dispositions have been revealing (Trehub, 2000, 2003a; Trehub \& Hannon, 2006). They have provided evidence that newborns dispose of amazing perceptual abilities with respect to spectral processing abilities (Trehub, 2003b, Hannon \& Trehub, 2005) and the recognition of primary sound features such as pitch and rhythmic processing (Winckler, Háden, Ladinig, Sziller \& Honing, 2009). The characteristics of the songs between mothers and infants, which are typically found in all cultures (motherese and lullabies) provide additional evidence for these claims: mothers capitalize on processing capacities that seem to be innate and young infants seem to be responsive to this kind of singing in ways that appear to be inborn (Masataka, 1999). Mothers, in infant-directed singing, sing more slowly, at a higher pitch level, with exaggerated rhythm, and in a more loving or emotionally engaging manner than when singing alone (Trainor, Clark, Huntley, \& Adams, 1997). 
These universals of auditory or musical pattern processing have provocative parallels in universals or quasi-universals of musical structure (Trehub, 2000). As such, it is arguable to define low-level universal features that constitute the building blocks of an inherent capacity for musical interaction upon which cultural variation is built and/or constrained. Bispham (2009-2010) conceives of them in terms of music's evolutionary design features (musical motivation, musical pulse and musical pitch) to the extent that they are species-specific, specific to the context of musical engagement, and universally present. They are related to temporal organization of action (pulse and rhythm) and frequency-based organisation (melody and harmony) and are widely considered to be the fundamental, descriptively and neurophysiologically distinct features of music. Musical pulse and musical pitch, moreover, appear to provide a framework for synchronous interpersonal action and coordination.

As to musical pulse, there are actually sophisticated assessment techniques - mismatch negativity or MNM - which have demonstrated that newborns show discriminative brain responses as a result of violating some regular features of primary sound features in a sound sequence (Winckler et al., 2009). As such, newborns seem to be sensitive to periodicities and to temporal stimulus parameters, such as beat detection and entrainment with movement and sound. Musical pitch, on the other hand, is built upon a [592] primary ability to produce and engage with a sustained stable fundamental frequency $F_{o}$ and the ability to create or process certain relationships between pitches and with reference to sustained yet variable tonal areas. The production of this sustained fundamental frequency, as well as more complex forms of musical pitch, further, are reliant upon an ability to produce sound that independently varies in loudness, pitch, and timbre (Bispham, 2009-2010).

As such, there is growing evidence for the hypothesis that music perception is constrained by innate, possibly human- and music-specific principles of organization of sensory stimuli. There are, in fact, a few basic features of music that correspond to some perceptual traits which are determined in part by innate constraints and which can be generalized across cultures, such as relative pitch, the importance of the octave, intervals with small integer frequency ratios, tonality, diatonic scales, transposability, meter regularity and perhaps also elementary musical preferences, (Lehman, Welker \& Schiefenhövel, 2009-2010; McDermott $\&$ Hauser, 2005). As to the perceptual level, evidence has been provided for melody recognition and preference for consonance (McDermott and Hauser, 2005), for tonal encoding of pitch (Peretz, 2006) and for beat perception and synchronization (BPS) (Patel, 2006). 
Innate biases for music, if they exist, should somehow be instantiated in the brain in order to be really innate. At present, however, there is little evidence for neural circuitry dedicated specifically to music-specific adaptation, with the exception of the mechanisms for detecting pitch changes (Peretz \& Morais, 1989) and for representing tonal hierarchy (see McDermott \& Hauser, 2005 for an overview). The evidence is quite compelling, however, for considering musical pitch processing as a module in Fodor's sense because this processing component meets the requirements for domain-specificity, brain localization, and innateness (Peretz, 2006). The other perceptual biases may result probably from general-purpose features of the auditory system, which are general perceptual strategies rather than music-specific.

In addition to those innate biases, the available evidence suggests that other aspects are learned through cultural exposure. The sensitivity that adults have to musical key structure (Krumhansl, 1990; Trainor \& Trehub, 1992) and culturally specific scale structures, e.g., is not present in infants (Lynch et al., 1990), which suggests that it is acquired through experience.

\section{Distinctions and observables: from delimitation to semanticity}

Human beings rely on universal perceptual processing dispositions, which are genetically prewired. There is, in fact, a whole body of empirical research about wired-in reactivity to environmental stimulation, as evidenced by studies on sensory coding and the search for psychophysical commonalities. Sensory coding is characterized by neural coding strategies that are used in representing and processing sensory information. It is one of the rare domains which allow a kind of low-level automatic and elementalist approach to the processing of information with mapping functions between perceptual input and behavioral reactions that suggest some kind of causal relationships (Uttal, 1978, 1998). Psychophysics, on the other hand, is the science of the response of organisms to stimulus configurations. Being concerned basically with the relations between the dimensions of physical stimuli and those of sensory [593] experiences, it sees the responses as varying with the stimulus but being relatively invariant from person to person. As a science it thus tries to contribute to the 'invariance' of the human nature and, as such, stresses the 'nature' side of perceptual processing. 
Sensory psychophysics — and coding theory — has progressed considerably towards an understanding of the information processing carried out by sensory systems. It is one of the most mature of the psychobiological sciences and has evolved around the central axiom of psychobiological equivalence between percepts, experience and thought (Uttal, 1978, pp. 16 and 26). It addresses the central question whether there is some lawfulness in the coordinations between sounding stimuli and the responses of music users in general. The answer, however, is not obvious: there are psychophysical commonalities, which can be considered to be universal, but there is a lot of subjectivity as well. It makes sense, therefore, to conceive of biological and perceptual constraints, which act as 'biases', rather than to think in terms of 'causal relationships' between sounding stimuli and reactions to these stimuli. It allows, further, to consider the idiosyncrasies of the individual music user in his/her attempts to make sense out of the sounding flux and to conceive of the process of sense-making in terms of epistemic autonomy.

Sensory processing, thus, cannot solely account for the particularity of the musical experience. Though the empirical findings claim consistency in sensory responses, there is also a lot of freedom in the process of sense-making, which is induced by the impingement of physical stimuli upon the listener's sensory system. It should be argued, therefore, to go beyond the computation of correlations between a single perceptual stimulus and the perceptual experience. Or put in other terms: sensory stimulation is not as causal and linear as would be assumed, even at the low level of sensory processing (Uttal, 1998: 200).

The question remains, therefore, what listeners actually hear when they are involved in a listening situation. Do they rely on universal perceptual processing dispositions, which are rather general, or do they rely on music-specific attentional strategies? The latter, obviously, refer to the nurture side, the former to the nature side of the nature/nurture dichotomy. Both ways of processing, however, are not opposed to each other, but are complementary (Reybrouck, 2008) with a dynamic tension between music-specific and general-acoustic processes of auditory discrimination. It should be borne in mind, however, that the auditory system was devised primarily as "an instrument for detecting and localizing a distant acoustical disturbance, and as a contributor to the identification of the disturbing events ... [mostly] within an action-oriented behavior" (Wallin, 1991, p. 231). Acute perception, therefore, seems to have an evolutionary advantage in providing better fitness for interactions with a given environment. The end result of this screening behavior, however, does not 
merely depend on the relationship between the physical properties of the stimulus and the efficiency of the activated auditory system. As Wallin puts it: "The stimulus as a releaser of a purposive behavior ... is weighed by the organism not only by means of auditory capacity in analyzing an acoustical event, but through a simultaneous evaluation of the event's significance as well” (Wallin, 1991, p. 231).

This brings us to the role of cognitive penetration in the perception of auditory events, which means that the critical locus of perceptual experience should not be explained in reductionist terms that 'peripheralize' the explanation of perception by locating it in the earliest or lower levels of the sensory pathways. The determination [594] of the perceptual response depends largely on factors beyond the raw physical attributes of the stimulus (Uttal, 1998, p. 3), with higher levels of nervous activity determining the perceptual outcome to a great extent. This is the case, as soon as environments get more unpredictable and complex. The organism, then, must rely not only on highly evolved genetically based biological mechanisms that trigger reactions in a quasi-automatic way, but also on survival strategies that go beyond instinctual mechanisms of reactivity. The latter, as a rule, have developed in society and are transmitted by culture. They require consciousness, reasoned deliberation and willpower with response selections that are no longer reducible to the functioning of a set of neural circuits in the older structures of the brain (Damasio, 1994, p. 127).

The problem of perception, then, is a question of taxonomy in wich the individual organism must "not only identify and classify things but also decide what to do in the absence of prior detailed descriptive programs handed down by evolution" (Edelman, 1987, p. 26). The solutions to this problem should be framed within the organism's own ecological niche and for its own adaptive advantage, with the mind operating in a 'discrete' manner that assigns stimuli to a set of distinct and ordered categories. This is categorical perception that reduces numerous elements to one single class. It involves a kind of generalization that reflects the qualitative distinction between sensation and thought (Vygotsky, 1962). Or to put in another way: assigning sense and meaning to an object involves a generalized reflection of reality that marks the difference between isolated and categorized perception (Vygotsky, 1978).

The same conception has been advocated also by Bruner (1957)_-"perception involves an act of categorization"- and an echo of this categorical approach to perception can be found in the work of Edelman (1987). Every sensory structure that acquires a repeatable and permanent 
character can thus become a possible object of discrimination and identification. As such, it is eligible to function as an element of a 'psychologically satisfying set' of manageable units, which can be considered as a subset of a more encompassing universe of sensory stimuli. Psychological space, in fact, is a limited space, as the potential continuum of physical stimuli is not paralleled by a psychological continuum. There is, in fact, no strict psychobiological equivalence between stimuli, neural activity and meaningful elements. What is needed, is a transition from neural activity to perception and cognition, or applied to music: the transformation from mere sensory detection of acoustic stimuli to meaningful musical elements.

This transition holds an element of delimitation and semanticity, which distances the listener from the music in going beyond the constraints of 'perceptual bonding'. In taking distance from the richness of the concrete sounding experience, he/she relies on discrete labels or categories rather than on continuous processing of the sonic unfolding through time, somewhat an analogous to the distinction between exploring and observing, which is 'analogcontinuous', and labeling and identifying, which is 'digital-discrete' (Pattee, 1995). The former is more sensitive, as it works outside of the limitations of fixed thresholds. It is also closer to the real world which is not segmented, but which presents itself in ranges and continuous transitions. The latter constrains the real world from a relatively large or continuous set of values to a relatively small set of discrete and quantized values, which have the advantage of distinctness and communicability. They allow the knower, however, to share an experience without actual living this experience, highlighting the economy of abstraction as against the subtlety of experience, or stated in another way: the difference [595] between an analogue image system and a language-like or propositional system (Watkins \& Dyson, 1985 , p. 72). In passing from the sensory to the cognitive representation, there is, in fact, a systematic stripping away of components of information which reduces the experience of the phenomenally rich thing to only one or some of its components (Dretske, 1985). This is a process of digitalization or conceptualization with a piece of information being taken from a richer matrix of information in the sensory-analog representation and featured to the exclusion of all else. 'Discrete-digital', in this sense, means that something is apprehended in an all-ornone fashion, featuring its distinctive features rather than its qualities.

Digitalization and conceptualization, further, focus on generic features that combine the maximum of information with the least cognitive effort. They consider those things as 
equivalent that can be distinguished from each other, but which can be subsumed under the same conceptual category. As such, they neglect the idiosyncrasies in order to allow discrimination at a more abstract level of similarity, allowing to recognize things rather than to experience them and to differentiate between things as the result of interventions by the mind. Nature and life, in fact, are continuous rather than discrete. They call forth epistemological interactions with the world in order to create distinctions and observables.

Translated to the realm of music, this should mean that the listener makes distinctions in the sounding flux, which is continuous. This discretization of a continuous phenomenon can be so fine-grained that it reflects the idiosyncrasies of the particular experience. It is possible, however, to go beyond the particularities of concrete experiences and to generalize from mere particulars to broader and more encompassing categories. In doing so, there is the danger of distancing and polarization between the listener and the music with the distinctions being suited for 'sharing' experiences between listeners rather than 'experiencing' the idiosyncrasies of the experience proper.

The delimitation of discrete elements, however, is not sufficient ground for conceiving of them as music. Beyond the level of distinctions and observables, there is a level of higherorder structures, which can be built through combinatorial arrangements of discrete unitary elements, both simultaneously and in succession. As such, there is a striking parallel between music and language: both of them use discrete building blocks and rules of combinatorial syntax. The combinatorics, however, is not the whole story, as both music and language make extensive use of expressive phrasing and modulation of the sound (Frayer \& Nicolay, 2000). This brings us to the role of affective as against referential semantics (see below).

\section{Reacting to modulated sound: emotion and meaning}

The transition from mere auditory perception to 'focal listening' entails a moment of semanticity with sounds or groupings of sounds being taken apart and differentiated from an amorphous sonorous background. As such, they can become the objects of mental pointing, as a means for identifying adequately the place and time of their unfolding. The major advantage of this approach is the allocation of the points of focal attention in a real-time and contextual 
embedding (Reybrouck, 2009, 2010). Rather than providing merely a post-hoc description of music as an artifact, which proceeds mostly out of the time of actual unfolding, it picks up or points to sounds in [596] the context of a referential exchange between the music and the listener. To speak of the sound of 'a' clarinet, e.g., does not involve this referential exchange; to speak of the sound of 'this' clarinet, or referring back to the clarinet sound we just heard as 'that sound' or simply 'that', however, does involve a referential exchange as it is only obvious for the participants of the previous listening situation who shared an act of joined attention.

This sharing of attention is typical of the 'deictic' field of meaning, as Bühler coined the term (1965/1934, see also Kita, 2003 and Fillmore, 1982). It calls forth an indexical - the index is the pointing finger - approach to sense-making with a distinction between the deictic and symbolic field of meaning and the use of 'pointing words' as opposed to 'naming words'. The former hold a dynamic-vectorial approach to the world and are directive in nature; the latter rely on distancing and polarization between the cognizer and the world. Speaking of a violin in general, for instance, does not imply the physical presence of the instrument. It can be conceived at a merely symbolic level, as can be done with all meaningful units of a linguistic lexicon. Listening to the sound of a real violin, on the contrary, holds a dynamic approach that captures the temporal unfolding of the articulation of the sound. Deictic procedures and expressions are thus related to the 'field of pointing'. They focus the hearer's attention towards specific elements of a deictic space (Ehlich, 1982) and realise a form of joint attention, the sharing of overlap in the focal attention of the parties of a referential exchange. As such, they provide a source of reference that locates individual elements in context, rather than simply tagging them. Having their origin within the situation of a referential exchange, with the meaning of deictic expressions depending crucially on 'when', 'where' and 'by whom' they are used, they can be systematized in terms of personal, spatial and temporal deixis (the socio-spatio-temporal axes) with a zero point (the Origo) being fixed by the person who does the referential exchange (I), the place of utterance (here) and the time of utterance (now) (Fillmore, 1982). Deictic expressions, therefore, have to be defined with reference to the referential event, its participants and its settings in order to allow an operational description of space/time moments and their relations to the position and time of utterance.

It is not difficult to apply this to the realm of music. Listening, as a process, can be considered as a referential exchange between the music and the listener, with the act of mental pointing 
as "an internal reconstruction of an external operation", transfiguring a merely object-oriented movement — such as grasping — to a mental operation (Vygotsky, 1978, p. 56). This mental pointing to the music provides a contextual embedding of the listening process with a major reference to the actual sounding situation and a corresponding direction of attention. The latter can be considered as a primitive marking system, which mostly begins with the emergence of a kind of quality in combination with an insistent particularity, - e.g. 'this is important', or 'that is difficult' (Whitehead, 1968, p. 5). The question should be addressed, therefore, which qualities and which particularities are eligible for selection and for delimitation. The mere multiplicity of possible objects of focal attention, in fact, requires a selection with respect to their abundance and this, in turn, calls forth the notion of relative importance.

Making sense of music, accordingly, can be seen as a process that relies on the simultaneous usage of an experiential and mentalist approach to the understanding of music as it sounds [597] (Reybrouck, 2001a, 2005a, b). There is, in fact, a distinction between registering the sounds and understanding them, even at a level that is below the level of full consciousness. What matters, in this combined approach, is the process of listening as an articulation over time which values the richness of the sensory experience of the sounding music — which is continuous - as well as the kinds of conceptualizations by the listener as the music proceeds. This way of music processing is 'coperceptual' rather than 'autonomous', which means that it proceeds in the presence of the appropriate sensory input, relying on perceptual immediacy rather than on symbolic representation without perceptual bonding (Reybrouck, 2001b). As such, there is an analogy with the distinction Langacker has drawn between processual predication and episodic nominalizations. Processual predications follow the temporal evolution of a situation and involve a continuous series of states that represent different phases of the process as occupying a continuous series of points in conceived time. Episodic nominalizations, on the contrary, refer to just a single instance of the process (Langacker, 1987, pp. 191 and 244).

This brings us to two different ways of dealing with the sounds, which Frayer \& Nicolay have coined as the acoustic and vehicle mode of sound perception. The former refers to the "immediate, on-line, emotive aspect of sound perception and production. It deals with the emotive interpretation of musical sound patterns throughout two processes that [are called] "sound emotion" and "sentic modulation"”. The latter refers to "the off-line, referential form 
of sound perception and production. It is a representational mode of music operation that results from the influence of human linguistic capacity on music cognition." (Frayer \& Nicolay, 2000, p. 272).

Both modes of sound perception are related to the linguistic distinction between referential and affective semantics (Molino, 2000), with the former referring mainly to the study of the lexicosemantic dimension of language and the latter being more closely related to the domain of musical meaning. Affective semantics, further, is not couched in emotionally neutral cognitive representations, but carries the mark of the ties that connect humans and their environment. As such, it depends on mechanisms that are associated with evolutionary older anatomical structures such as the brain stem and the limbic system (Edelman, 1992).

Musical meaning, accordingly, cannot be stated merely in objective and neutral terms. It is dependent on emotion-integrating regions in the human brain, which can invoke and arouse emotions (Blood \& Zatorre, 2009-2010; Brown, Martinez \& Parsons, 2004; Menon \& Levitin, 2005; Panksepp, 2009-2010). Music, in fact, is commonly called the language of emotions and is a powerful tool for emotion and mood modulation. Much of the 'power' of music relies on the fact that it can trigger ancient evolutionary systems such as the limbic system and related structures. Two questions should be raised, therefore: (i) what are the mechanisms behind this inductive power, and (ii) what are musical emotions proper?

Emotions in general and musical emotions in particular can be viewed as adaptive responses that can be aroused silently in every human being. As to the emotions in general, Damasio has made an attempt to provide a working definition by defining 'emotions-proper' — such as happiness, sadness, embarrassment or sympathy — as a complex collecton of chemical and neural responses, which form a distinctive pattern. These response patterns are produced automatically by the brain as the result of the presence of an object or event that operates as an "emotionally competent stimulus' [598] and that triggers the emotion. The brain, in this view, reacts with a specific repertoire of actions, which are prepared by evolution as well as learned as the result of previous experiences. They result in a temporary change in the state of the body and those structures of the brain that map the body and support thinking. The ultimate result of the responses, then, is the placement of the organisms in circumstances that are conductive to survival and well-being (Damasio, 2004, p. 53). As to the musical emotions, they can be conceived as the product of specialized neural structures that operate in a way that 
resembles the operation of reflexes. As Peretz puts it: "musical emotions would occur with rapid onset, through automatic appraisal, and with involuntary changes in physiological and behavioral responses" (2001, p. 115). Emotions, in this sense, are experienced typically as happening to us, not to be chosen by us.

Emotions, in this operational approach, rely on processing mechanism that are below the level of conscious control and that are situated in subcortical emotion-processing areas of the brain. Through the release of chemical molecules into the blood and the spread of neural activation to various brain centers and muscles, their experience is connected with a lot of physiological responses, from muscle contraction, to changes in breathing and heart rate, to changes in blood flow in various parts of the body, to sweating (Trainor \& Schmidt, 2003). Studies using self-report and direct measures of autonomic function have shown, in fact, that listening to music does produce autonomic changes associated with emotion processing such as shivers down the spine, laughter, tears, and lump in the throat.

The question should be addressed, further, which stimuli can function as 'emotionally competent stimuli'. Though there is a lot of subjectivity in the way listeners react to music, there has been a body of research, which has reported on psychophysical dimensions of music as well as physiological reactions that have shown to be their correlates (Krumhansl, 1997; Scherer \& Zentner, 2001; Peretz, 2001). Dimensions such as musical tempo, timbre, and loudness seem to be important, in addition to increases in perceived complexity, which has been shown to be associated with arousal responses. The mechanisms behind these dimensions are not culture-specific and may function as universal cues for the emotional evaluation of auditory stimuli in general. They seem to be grounded in the dispositional machinery of individual music users.

It can be hypothesized that these emotional evaluations may have originated as adaptive responses to acoustic input form threatening and nonthreatening sounds (see Balkwill \& Thompson, 1999, for an overview). The reactions, further, are mostly physiological constants, such as the induction or modification of arousal, which can be defined in its most narrow sense as a stimulation of the autonomic nervous system. It plays a major role in many studies of music and emotion, but many questions are still open with regard to their affective and interpretative components. 
Some of these reactions can be subsumed under the sensations of peak experience, flow and shivers or chills (Panksepp, 1995), as evidence for particularly strong emotional experiences with music (see Gabrielsson \& Lindström, 2001 and Bispham, 2009-2010, for an overview). These peak experiences, however, are rather rare and should not be taken as the starting point for a generic comparative perspective on musical emotions. Some broader vitality effects or creation of tensions and expectancies may engender some music-specific emotional reactions as well.

[599] As such, there seem to be a number of quasi-universal reactions to music, which are not culture-specific and which may function as universal cues for the emotional evaluation of auditory stimuli in general. In a more restricted sense, there has been empirical research as to the physical reactions to music as an emotionally competent stimulus, such as shivers down the spine, laughter, lump in the throat, tears, goose pimples, racing heart, yawning, pit of stomach sensations, sexual arousal, trembling, flushing/blushing, and sweating (Sloboda, 1991). Attempts have been made, also, to define those music-structural features that can be associated with these physical responses. Typical examples are descending cycles of fifths in harmonic progressions, melodic appoggiaturas, melodic or harmonic sequences, enharmonic change, harmonic or melodic acceleration to cadence, delay of final cadence, new or unprepared harmony, sudden dynamical or textural change, repeated syncopation and a prominent event that comes earlier than the listener is prepared for (Sloboda, 1991).

It can be argued, further, that the affective impact of music is generated by the 'modulation' of sound with a rather close connection between primitive emotional dynamics and the essential dynamics of music. Evolution, according to Panksepp (2009-2010), has given emotional sound special time-forms that arise from frequency and amplitude modulation of relatively simple acoustic patterns. These emotional sounds can be considered as innate release mechanisms that generate instinctual emotional actions (Burkhart, 2005; Hauser, 1996). It has been shown, in fact, that certain basic emotional systems of the brain, have evolved, as evidenced by measuring strong affective feelings that have been provoked by electrically stimulating subcortical brain regions across a large number of species (Panksepp, 2005). There are, further, species-typical emotional sounds associated with such arousals, the most complex of them being largest in primates (Jürgens \& Hage, 2007). There is abundant evidence, however, of the same types of vocalizations in 'lower' mammals with as clearest examples the separation calls and other social signals (Hauser, 1996; Newman, 1988, 2007). 
The emotional dynamics, further, have characteristic 'force-time functions' that Clynes has coined as sentic forms (Clynes, 1973, 1977). They rely on sentic modulation, which is a general modulatory system that is involved in conveying and perceiving the intensity of emotive expression by means of three graded spectra: tempo modulation (slow-fast), amplitude modulation (soft-loud) and register selection (low pitch-high pitch). It hints at an important aspect, namely how expressive qualities vary and change in a dynamic way. Emotional expressions, in fact, are not homogeneous over time, but many of music's most expressive qualities relate also to structural changes over time. The whole process is somewhat analogous to the well-known rules of prosodic contours (Frick, 1985), which encompass our most basic idea about intonation. They refer to the local risings and fallings, quickening and slowing, and loudenings and softenings that are involved in expressively communicating meanings and appear to be invariant across modalities of expression - this is Clynes' equivalence principle, which states that a sentic state may be expressed by any number of different output modalities in humans, such as speech, music, and gesture (Clynes 1977: 18, see also Frayer \& Nicolay, 2000).

These prosodic contours are to be found in vocal expressions in general (Juslin, 2001). They are most obvious, however, in the practices of caregivers all over the world (see above) who sing to young infants in an 'infant-directed' singing style [600] which is probably used in order to express emotional information and to regulate the infant's state (Trainor and Schmidt, 2003). As such, there seems to be a linkage between acoustic dynamics and emotional dynamics, which appear to be biologically grounded and which are evidenced to some extent in Clynes' sentic forms. These emotional signals, along with the evolved appreciation of temporal progressions (Clynes \& Walker, 1986), can generate, relive, and communicate emotion intensity, helping to explain why every basic human emotion is easily rendered through music (Juslin \& Sloboda, 2001).

\section{From sound to music}

Some sounds can act as emotionally competent stimuli. Not all sounds, however, do, and even music does not always act this way. It is possible, in fact, to conceive of music as organized sound without any reference to invoked emotions. This addresses the question of musical 
signification, which has been challenged vigorously by the formalist tradition in musicology_-from Hanslick to Stravinsky—, which stated that music, by its very nature, is incapable of expressing anything. This provocative statement has influenced profoundly the long-lasting debate between absolutists and referentialists, who conceive of music as a mere formal structure that does not refer to something outside of the music as against a conception of music in terms of sound as reference. There is, however, a reconciliation of both viewpoints by seeing music in terms of the above-mentioned acoustic mode versus the vehicle mode of perceiving, producing and responding to musical sound patterns, which act in parallel and are alternative but complementary interpretations of the same acoustic stimuli (Frayer \& Nicolay, 2000).

The two modalities are related to the distinction between representational and rhythmoaffective semantics with the former referring to a lexicon of denotable objects or events, and the latter referring to processes which involve the body, its movement, and the fundamental emotions that are associated with them (Molino, 2000). Affective semantics, further, is closely related to the acoustic mode of processing, which, in turn, refers to the immediate, online, emotive aspect of sound perception and production. It is concerned with the qualitative aspect of sound, rather than with its denotative aspect, and this may be one of the critical distinctions between 'sound as music' and 'sound as language'. In contrast to language, which has a lexisosemantic dimension, there is no standard lexicon for reference in music. There is, however, a possibility to conceive of musical reference in terms of self-reference by using a weaker version of lexical meaning that defines sounds or groupings of sounds as things that can be 'denoted' (musical denotata) (Reybrouck, 1999, 2004). These denotata, then, should be the elements of a self-referential semantics and denotation should be defined on the basis of a process of recognition through identification and differentiation (Martin, 1978; Reybrouck, 2009, 2010). Music, in this sense, is the carrier of immanent meaning with the denotative aspect of musical semantics not being reducible to an extramusical reference in the strictest sense. The reference collapses, so to say, to blend with the sonorous unfolding, on condition that the denotatum acquires some conceptual quality. The denotation of a pitched note, e.g., does not refer to the vibratory sound event, but to the recognition of the [601] category or class that embraces its actualization (the note ' $d$ ', e.g.). The reference, therefore, is not external but internal to the musical system (Imberty, 1979). 
Musical denotata, thus defined, are closely linked to the process of sense-making. They are not to be identified as concrete-sounding sonorous events, but as the abstract terms that refer to them. What is meant is not the physical datum, but the datum that is disengaged from its existential dependency from the particular thing it is referring to. To define denotata thus implies a generalized reflection of sonic reality, which can be formalized as assigning attributes to the sensory material. This is a 'proposition' in logical sense with the sounding material as 'subject' and the attributes as 'predicate'. This brings us to the act of mental pointing, again, which can be predicative if at least there is some generality to be assigned to the entity, which is pointed at. This fusion of a large generality with an insistent particularity is related to the distinction between direct or immediate knowledge, which relies on particularity, and symbolic knowledge, which relies on generality (Whitehead, 1927, p. 13). It calls forth the role of presentational immediacy which is important in setting out the borders between perception and consciousness, with the latter involving complex mediated processes that supplant the immediacy of natural perception (Vygotsky, 1978).

As such, there is a continuum, or at least some complementarity between the on-line perceptual and off-line referential mode of sound perception, stressing both the role of presentational immediacy (on-line), as well as taking distance from the perceptual flux (offline). The latter, especially, is a representational mode that reflects the influence of human linguistic capacity on music cognition: it allows listeners to 'share' experiences rather than to 'revive' them. Musical denotata, then, are considered in terms of recognizability, prototypicality and communicability rather than in terms of their perceptual qualities. What matters, then, is not merely the accurate acquisition of information from the environment, but the correlation of modes of perception between individuals, which are interacting in the same cultural system. As such, they can share perception with the creative emergence of perceptual capacities through games of social interaction (Bown \& Wiggins, 2009-2010) and this brings us to the social aspect in dealing with music.

It is possible, further, to make sense of music at the level of individual sounds. As such, there is a distinction between sound and music, with musical sounds being characterized by aspects of harmonicity and regularity, which make it possible to set them apart from the acoustic background as a whole. Musical sounds, in this view, entail a hermeneutic moment and a first level of self-reverential semantics. They involve an aspect of self-similarity in the sense that they can be recognized as such (sounds as sounds). Musical sounds, however, have 
combinatorial possibilities as well, both in a simultaneous and successive way. As such, they can generate a phenomenal diversity of musical structures, which is based upon the combination of discrete elements as illustrated by the particulate principle of self-diversifying systems (Abler, 1989). Several independent natural systems — such as chemical interactions, biological inheritance and human language - appear to exhibit change by a process of variation and selection of dynamically stable, particulate units. The particulate principle, then, holds that structures, which have an infinite range of possibilities, are based on particles, which can be combined. The constituents of such systems can be of any kind, but discrete durations in the temporal domain and sets of discrete pitches in the frequency domain are prototypical examples that are applicable [602] to the domain of music. It is possible, therefore, to conceive of particulate combinations across the pitch and time dimension of spectro-temporal space (Merker, 2002).

The introduction, finally, of additional dimensions or qualities of musical denotata, which allow a quantitative description of sound characteristics (amplitude envelope, amplitude and phase spectrum, spectral envelope, harmonicity, formants, noise level, etc., see Serra, 1997) raises them to the level of multidimensional constituents which can be conceived as auditory events. These qualities, however, are not gratuitous: they make it easier to delimit sounds as sounds and to share attention with other listeners who can focus on the same sounds. As such, they refer to the denotative potential of music as a self-containing semantic system - with sounds referring mainly to themselves - as well as to the entrainment effect of music, as exemplified in movements that are invoked by music, with dance as a prototypical example. Both music and dance share the tendency to have events uniformly spaced in time, proceeding by what is coined as isochronicity (Dean, Byron \& Bailes, 2009-2010). People, in fact, can move together in synchrony, but this requires temporal anticipation and entrainment. It seems, further, that amongst animals only humans can generate and align with a regular pulse, be it musical or bodily (Patel, 2006; Wallin et al., 2000). As such, music can favor the formation of coalitions and promote cooperative behavior toward group members through the opportunities that it offers for the formation and maintenance of group identity, group synchronization between members of a group, and group catharsis or the collective expression and experience of emotion (Brown, 2000).

Music, and even musics all over the world, are not reducible to the perceptual level only. A generalizable definition of music, therefore, would refer to music's two roots in sound and 
movement. Putting these premises together, Cross have made an attempt to yield an operational definition of music or musics: "Musics can be defined as those temporally patterned human activities, individual and social, that involve the production and perception of sound and have no evident and immediate efficacy or fixed consensual reference." (Cross, 2001a, p. 33).

\section{Conclusion}

This paper deals with mechanisms of musical sense-making. Revolving around the nature/nurture dichotomy, it considers the role of the music listener and his/her dispositional machinery to respond to sounding music. Starting from the assumption that music is a selfcontaining semantical system with elements that can be delimited at will, it argues that the delimitation of elements is not totally arbitrary but constrained. The musics of the world have capitalized on these constraints in order to entrain people and to share focal attention. Music, in this view, has emancipated itself from the level of mere acoustic processing of sounds to a functional description in terms of perceptual pregnancy and predicability, allowing music users to share experiences, shaped by their dispositional machinery and through epistemic interactions with the sounds. These interactions are partly autonomous and partly constrained but all of them stress the realization of systemic cognition in the context of a living system's interactions with the environment. As such, listeners can be conceived as adaptive devices, which can build up new semiotic linkages with the sounding world. These linkages can be considered as by-products of both biological [603] and cultural evolution and can be helpful in providing coordinative frameworks for achieving diversity of thought, cultural invention, social interaction and optimal coregulation of affect.

\section{References}

Abler, W. (1989). On the particulate principle of self-diversifying systems. Journal of Social and Biological Structures, 12, pp. $1-13$. 
Balkwill, L.-L. \& Thompson, W. (1999). A cross-cultural investigation of the perception of emotion in music: Psychophysical and cultural cues. Music Perception, 17, 43-64.

Barkow, J.H., Cosmides, L. \& Tooby, J. (1992). The Adapted Mind: Evolutionary Psychology and the Generation of Culture. Oxford: Oxford University Press.

Bispham, J. (2009-2010). Music's “design features”: Musical motivation, musical pulse, and musical pitch. Musicae Scientiae, Special Issue 2009-2010, 41-61.

Blacking, J. (1973). How Musical is Man? Seattle: Universtiy of Washington Press.

Blacking, J. (1987). A common-sense view of all music. Reflections on Percy Grainger's contribution to ethnomusicology and music education. Cambridge: Cambridge University Press.

Blood, A. J., \& Zatorre, R. J. (2001). Intensely pleasurable responses to music correlate with activity in brain regions implicated in reward and emotion. Proceedings of the National Academy of Sciences, USA, 98, 11818-23.

Bown, O. \& Wiggins, G. (2009-2010). From Maladaptation to Competition to Cooperation in the Evolution of Musical Behaviour. Musicae Scientiae, Special Issue 2009-2010, 387411.

Bregman, A. (1990). Auditory Scene Analysis: The Perceptual Organization of Sound. Cambridge, Massachusetts: The MIT Press.

Brown, S. (2000). Evolutionary Models of Music: From Sexual Selection to Group Selection. Perspectives in Ethology, 13, 13, 231-281.

Brown, S., Martinez, M. J., \& Parsons, L. M. (2004). Passive music listening spontaneously engages limbic and paralimbic systems. NeuroReport, 15, 2033-37.

Bruner, J. (1957). On Perceptual Readiness. Psychological Review, 64, 123-152.

Bühler, K. (1965 [1934]). Sprachtheorie: die Darstellungsfunktion der Sprache. Stuttgart: Gustav Fischer.

Burkhardt, R. W. (2005). Patterns of behavior. Chicago: University of Chicago Press.

Clynes, M. (1973). Sentics: Biocybernetics of emotion communication. Annals of the New York Academy of Sciences, 220 (3), 55-131.

Clynes, M. (1977). Sentics, the touch of emotion. Anchor, New York: Doubleday.

Clynes, M. \& Walker, J. (1986). Music as Time's Measure. Music Perception, 4,1, 85-120.

Cross, I. (2001a). Music, Cognition, Culture, and Evolution. In Peretz, I. \& R.Zatorre (Eds.). 2001). The Biological Foundations of Music. Annals of the New York Academy of Science, 930, 28-42.

Cross, I. (2001b). Music, Mind and Evolution. Psychology of Music, 29, 95-102. 
Cross, I. (2003a). Music and Evolution: Consequences and Causes. Contemporary Music Review, 22, 3, 79-89.

Cross, I. (2003b). Music, Cognition, Culture, and Evolution. In Peretz, I. \& R.Zatorre (Eds.). 2003b). The Cognitive Neuroscience of Music (pp. 42-56). Oxford - New York: Oxford University Press.

Cross, I. (2009-2010). The evolutionary nature of musical meaning. Musicae Scientiae, Special issue 2009-2010, 179-200.

Damasio, A. (1994). Descartes' Error: Emotion, Reason, and the Human Brain. New York: Harper Collins.

Damasio, A. (2004). Looking for Spinoza. Joy, Sorrow and the Feeling Brain. London: Vintage.

Dean, R. , Byron, T \& Bailes, F. (2009-2010). The Pulse of Symmetry: On the Possible CoEvolution of Rhythm in Music and Dance. Musicae Scientiae Special issue 2009-2010, 341-367.

D’Errico, F., Henshilwood, C., Lawson, G., Vanhaeren, M., Tillier, A.-M., Soressi, M., et al. (2003). Archeological evidence for the emergence of language, symbolism, and musican alternative multidisciplinary perspective. Journal of World Prehistory, 17, 1-70.

Dissanayake, E. (2000). Antecedents of the temporal arts in early mother-infant interactions. In N. Wallin \& B. Merker \& S. Brown (eds). The origins of music (pp. 389-407). Cambridge, MA: MIT Press.

Donald, M. (1991). Origins of the Modern Mind. Cambridge: Harvard University Press. Drake, C. \& Bertrand, D. (2003). The Quest for Universals in Temporal Processing in Music. In Peretz, I. \& R.Zatorre (Eds.). The Cognitive Neuroscience of Music (pp. 21-31). Oxford - New York: Oxford University Press,

Dretske, F. (1985). Précis of Knowledge and the Flow of Information. In H.Kornblith (Ed.). Naturalizing Epistemology (pp.169-187). Cambridge/London: MIT Press.

Durham, W. (1991). Coevolution: Genes, Culture and Human Diversity. Stanford, CA: Stanford University Press.

Edelman, G. (1987). Neural Darwinism. The Theory of Neuronal Group Selection. New York: Oxford University Press.

Edelman, G. (1992). Bright air, brilliant fire: On the matter of mind. New York: Basis Books. Ehlich, K. (1982), Anaphora and Deixis: Same, Similar, or Different? In Jarvella, R.J. \& W.Klein (Eds.). Speech, Place and Action. Studies in Deixis and Related Topics (pp.315-338).s Chichester - New York: John Wiley \& Sons,. 
Feldman, M.W. and Laland, K.N. (1996). Gene-culture coevolutionary theory. Trends in Ecology and Evolution, 11: 453-457.

Fillmore, Ch. (1982), Towards a Descriptive Framework for Spatial Deixis. In Jarvella, R. \& W.Klein (Eds.). Speech, Place, and Action. Studies in Deixis and Related Topics (pp.31-59). Chichester - New York: John Wiley,

Fleagle, J. (1999). Primate adaptation and Evolution. San Diego: Academic Press.

Frayer, D.W. \& C.Nicolay (2000). Fossil Evidence for the Origin of Speech Sounds. In Wallin, N., B.Merker \& S.Brown (Eds.). The Origins of Music (pp. 271-300). Cambridge, MA - London: The MIT Press.

Frick, R. (1985). Communicating emotion: The role of prosodic features. Psychological Bulletin, 97, 412-429.

Gabrielsson, A. \& E.Lindström. (2001). The Influence of Musical Structure on Emotional Expression. In Juslin, P.N. \& J.Sloboda (Eds.). Music and Emotion: Theory and Research (pp. 223-248). Oxford: Oxford University Press.

Goldschmidt, W. (1959). Man's Way: A Preface to the Understanding of Human Society. New York: Holt.

Gould, S. (1977). Ontogeny and Phylogeny. Cambridge (MA): The Belknap Press of Harvard University Press.

Gould, S., \& Vrba, S. (1982). Exaptation - a missing term in the science of form. Paleobiology, 8, 4-15.

Gratier, M. (1999). Expressions of belonging: the effect of acculturation on the rhythm and harmony of mother-infant interaction. Musicae Scientiae, Special Issue 1999, 93-122.

Handel, S. (1989). Listening. An Introduction to the Perception of Auditory Events. Cambridge - London: MIT Press.

Hauser, M. D. (1996). Evolution of communication. Cambridge, MA: MIT Press.

Hauser, M. \& McDermott, J. (2003). The evolution of the music faculty: a comparative perspective. Nature Neuroscience, 6 (7), 663-668.

Huron, D. (2003). Is Music an Evolutionary Adaptation? In Peretz, I. \& R.Zatorre (Eds.). The Cognitive Neuroscience of Music (pp. 57-75). Oxford - New York: Oxford University Press.

Imberty, M. (1979). Entendre la musique. Sémantique psychologique de la musique. Paris: Bordas.

Jürgens, U., \& Hage, S. R. (2007). On the role of the reticular formation in vocal pattern generation. Behavioral Brain Research, 182, 308-14. 
Juslin, P. (2001). Communicating Emotion in Music Performance: A Review of and Theoretical Framework. In: Juslin, P.N. \& J.Sloboda (Eds.). Music and Emotion: Theory and Research (pp. 309-337). Oxford: Oxford University Press.

Juslin, P.N. \& J.Sloboda (Eds.). (2001) Music and Emotion: Theory and Research. Oxford: Oxford University Press.

Kita, S. (2003). Pointing. Where Language, Culture, and Cognition Meet. Mahwah (N.J.): Erlbaum.

Krumhansl, C. (1990), Cognitive foundations of musical pitch. New York: Oxford University Press.

Krumhansl, C. (1997). An exploratory study of musical emotions and psychophysiology. Canadian Journal of Experimental Psychology, 51, 336-353.

Langacker, R. (1987). Foundations of cognitive grammar, Vol. 1., Stanford CA: Stanford University Press.

Lehman, C., Welker, L \& Schiefenhövel, W. (2009-2010). Towards an Ethology of Song: A categorization of musical behaviour. Musicae Scientiae Special issue 2009-2010, 321338.

Leroy, J.-L. (dir.) (2012). Actualités des Universaux en Musique / Topics in Universals in Music. Paris: Edition des Archives Contemporaines.

Levitin, D. (2006). This Is Your Brain On Music: The Science of a Human Obsession. New York: Penguin Books.

Lumsden, C. \& E.Wilson (1981). Genes, Mind and Culture. Cambridge: Harvard University Press.

Lynch, M.P., R. E.Eilers, D.K.Oller \& R.C.Urbano (1990). Innateness, experience, and music perception. Psychological Science, 7, 272-276.

Martin, S. (1978). Le langage musical. Sémiotique des systèmes. Paris: Klincksieck.

Masataka, N. (1999). Preference for infant-directed singing in 2-day-old hearing infants of deaf parents. Developmental Psychology, 35(4), 1001-1005.

McDermott, J., \& H Hauser, M. (2005). The origins of music: Innateness, uniqueness and evolution. Music Perception, 23, 29-60.

Menon, V., \& Levitin, D. J. (2005). The rewards of music listening: response and physiological connectivity of the mesolimbic system. Neuroimage, 28, 175-84.

Merker, B. (2002), Music: the missing Humboldt system. Musicae Scientiae, V1, 1, 3-21. Merriam, A.P. (1964). The Antropology of Music. Evanston, Ill: Northwestern University Press. 
Miereanu, C. \& X. Hascher (Eds.) (1998). Les Universaux en musique, Actes du 4e Congrès international sur la signification musicale. Paris: Publications de la Sorbonne.

Miller, G. (2000). Evolution of human music through sexual selection. In N.L.Wallin, B.Merker, and S.Brown (Eds.). The Origins of Music (pp. 329-360). Cambridge, MA: MIT Press.

Mithen, S. (2005). The singing Neanderthal: The origins of music, language, mind and body. London: Weidenfeld and Nicolson.

Molino, J. (2000). Toward an Evolutionary Theory of Music and Language, In Wallin, N., B.Merker \& S.Brown (Eds.). The Origins of Music pp. 165-176.. Cambridge, MA London: The MIT Press.

Nettl, B. \& Bohlman, P.V. (1991). Comparative Musicology and the Anthropology of Music. Chicago: University of Chicago Press.

Nettl, B. (2000) An Ethnomusicologist Contemplates Universals in Musical Sound and Musical Cultures. In Wallin, N; B.Merker \& S.Brown (Eds.). The Origins of Music (pp. 463-479). Cambridge, MA - London: The MIT Press.

Nettl, B. \& Bohlman, P.V. (1991). Comparative Musicology and the Anthropology of Music. Chicago: University of Chicago Press.

Newman, J. D. (ed) (1988). The physiological control of mammalian vocalizations. New York: Plenum.

Newman, J. D. (2007). Neural circuits underlying crying and cry responding in mammals. Behavioral Brain Research, 182, 155-65.

Panksepp, J. (1995). The emotional sources of 'chills' induced by music. Music Perception, $13,171-207$.

Oatley, K. (1992). Best Laid Schemes. The psychology of the Emotions. Cambridge: Cambridge University Press.

Panksepp, J. (1995). The emotional sources of 'chills' induced by music. Music Perception 13, 171-207.

Panksepp, J. (2009-2010). The emotional antecedents to the evolution of music and language. Musicae Scientiae, Special issue 2009-2010, 229-259.

Panksepp, J. \& Bernatzky, G. (2002). Emotional sounds and the brain: the neuro-affective foundations of musical appreciation. Behavioural Processes, 60, 133-155.

Panksepp, J. (2005). Affective consciousness: Core emotional feelings in animals and humans. Consciousness and Cognition, 14, 30-80. 
Parncutt, R. (2009-2010). Prenatal and infant conditioning, the mother schema, and the origins of music and religion. Musicae Scientiae, Special Issue 2009-2010, 119-250.

Patel, A. (2006). Musical Rhythm, Linguistic Rhythm, and Human Evolution. Music Perception, 24, 99-104.

Pattee, H. (1995). Artificial life needs a real epistemology. In F.Moran, A.Moreno, J.Merelo \& P.Chacon (Eds.). Advances in Artificial Life. Lecture notes in artificial intelligence (pp. 23-38). Berlin: Springer.

Peretz, I. (2001). Listen to the brain: a bioloical perspective on musical emotions. In: Juslin, P.N. \& J.Sloboda (Eds.). (2001) Music and Emotion: Theory and Research (pp. 105134). Oxford: Oxford University Press.

Peretz, I. (2006). The nature of music from a biological perspective. Cognition, 100, 1-32.

Peretz, I. \& J.Morais (1989). Music and modularity. Contemporary Music Review, 4, 277 291.

Piaget, J. (1967). Biologie et connaissance. Essai sur les relations entre les régulations organiques et les processus cognitifs. Paris: Gallimard.

Pinker, S. (1997). How the Mind Works. New York: Norton.

Reybrouck, M. (1999), The musical sign between sound and meaning. In I.Zannos (Ed.), Music and Signs, Semiotic and Cognitive Studies in Music (pp. 39-58). Bratislava: ASCO Art \& Science.

Reybrouck, M. (2001a). Biological roots of musical epistemology: Functional Cycles, Umwelt, and enactive listening. Semiotica, 134(1-4), 599-633.

Reybrouck, M. (2001b). Musical Imagery between Sensory Processing and Ideomotor Simulation. In R.I.Godøy \& H.Jörgensen (Eds.). Musical Imagery (pp.117-136). Lisse: Swets \& Zeitlinger.

Reybrouck, M. (2004). Music Cognition, Semiotics and the Experience of Time. Ontosemantical and Epistemological Claims. Journal of New Music Research, 33(4), 411-428.

Reybrouck, M. (2005a). A Biosemiotic and Ecological Approach to Music Cognition: Event Perception between Auditory Listening and Cognitive Economy. Axiomathes. An International Journal in Ontology and Cognitive Systems, 15(2), 229-266.

Reybrouck, M. (2005b). Body, mind and music: musical semantics between experiential cognition and cognitive economy. Trans. Transcultural Music Review, 9. Retrieved from: http://www.sibetrans.com/trans/trans9/reybrouck.htm 
Reybrouck, M. (2008). The Musical Code between Nature and Nurture. In M.Barbieri (Ed.), The Codes of Life: The Rules of Macroevolution (pp. 395-434). Springer: Dordrecht. Reybrouck, M. (2009). Similarity perception as a cognitive tool for musical sense-making: deictic and ecological claims. Musicae Scientiae. Discussion Forum 4B, 99-11.

Reybrouck, M. (2010). Music cognition and real-time listening: denotation, cue abstraction, route description and cognitive maps. Musicae Scientiae; Special Issue 1009-2010, 187202.

Rouget, G. (1985). Music and Trance: A Theory of the Music and Relations between Music and Possession. Chicago: University of Chicage Press.

Scherer, K.R \& Zentner, K.R .(2001). Emotional effects of music: production rules. In P. N. Juslin \& J. A. Sloboda (Eds). Music and emotion: Theory and research (pp. 361-392). Oxford: Oxford University Press,.

Serra, M.-H. (1997). Introducing the phase vocoder. In Roads, C., S.Pope, A.Piccialli \& G. de Poli (Eds.) (1997). Musical Signal Processing (pp. 31-90). Lisse: Swets \& Zeitlinger.

Sloboda, J. (1991). Music structure and emotional response: Some empirical findings. Psychology of Music, 19, 110-120.

Stevens, S. (Ed.). (1951). Handbook of Experimental Psychology. New York-London: Wiley - Chapman \& Hall.

Trainor, L. J., Clark, E. D., Huntley, A., \& Adams, B. (1997). The acoustic basis of preferences for infant-directed singing. Infant Behavior \& Development, 20, 383-396.

Trainor, L. J., \& Trehub, S. E. (1992). A compari-son of infants' and adults' sensitivity to Western musical structure. Journal of Experimental Psychology: Human Perception and Performance, 18, 394-402.

Trainor, L.J. \& L.A.Schmidt (2003). Processing Emotions Induced by Music. In Peretz, I. \& R.Zatorre (Eds.). The Cognitive Neuroscience of Music (pp. 310-324). Oxford - New York: Oxford University Press.

Trehub, S. (2000). Human Processing Predispositions and Musical Univerals. In Wallin, N., B.Merker \& S.Brown (Eds.). The Origins of Music (pp. 427-448). Cambridge, MA London: The MIT Press.

Trehub, S. (2003a). Musical predispositions in infancy: an update. In Peretz, I. \& Zatorre, R. (Eds.). The Cognitive Neuroscience of Music (pp. 3-20). Oxford: Oxford University Press.

Trehub, S. (2003b). The developmental origins of musicality. Nature Neuroscience, 6, 669673. 
Uttal, W. (1978). The Psychobiology of Mind. Hillsdale, NJ: Lawrence Erlbaum.

Uttal, W. (1998). Toward a New Behaviorism. The Case Against Perceptual Reductionism. Mahwah (NJ) - London: Lawrence Erlbaum Publishers.

Vygotsky, L. (1962). Thought and Language. Cambridge (MA), MIT Press.

Vygotsky, L. (1978), Mind in Society. The Developpent of Higher Psychological Processes (Eds. Cole, J. \& E.Souberman), Cambridge (MA) - London: Harvard University Press.

Wallin, N. (1991). Biomusicology. Neurophysiological and Evolutionary Perspectives on the origins and Purposes of Music. New York: Pendragon Press.

Wallin, N.L.; B. M Merker \& S. B Brown (eds) (2000 ). The origins of music (pp. 389-410). Cambridge, Mass.: MIT Press.

Watkins, A.J. \& M.C.Dyson (1985). On the Perceptual Organisation of Tone Sequences and Melodies. In: Howell, P., I.Cross \& R.West. Musical Structure and Cognition (pp. 71119). London: Academic Press.

Whitehead, A.N. (1927), Symbolism. Its Meaning and Effect. New York: Capricorn Books.

Whitehead, A.N. (1968), Modes of Thought. New York: The Free Press.

Winkler, I., G. P. Háden, O. Ladinig, I. Sziller \& H. Honing (2009). Newborn infants detect the beat in music, PNAS, 2468, retrieved from http://www.pnas.org/content/106/7/2468.full

Zatorre, R.J. \& I. Peretz (eds) (2001). The biological foundations of music. Annals of the New York Academy Sciences, vol. 930. 